\title{
The Role of Synovitis in Osteoarthritis pathogenesis
}

\author{
Carla R. Scanzello ${ }^{1}$ and Steven R. Goldring ${ }^{2}$ \\ ${ }^{1}$ Section of Rheumatology, Department of Biochemistry and Department of Immunology and \\ Microbiology, Rush University Medical Center, Chicago IL USA \\ ${ }^{2}$ Hospital for Special Surgery and Weill Cornell Medical College, New York NY USA
}

\section{Abstract}

Research into the pathophysiology of osteoarthritis (OA) has focused on cartilage and periarticular bone, but there is increasing recognition that $\mathrm{OA}$ affects all of the joint tissues, including the synovium (SM). Under normal physiological conditions the synovial lining consists of a thin layer of cells with phenotypic features of macrophages and fibroblasts. These cells and the underlying vascularized connective tissue stroma form a complex structure that is an important source of synovial fluid (SF) components that are essential for normal cartilage and joint function. The histological changes observed in the SM in OA generally include features indicative of an inflammatory "synovitis"; specifically they encompass a range of abnormalities, such as synovial lining hyperplasia, infiltration of macrophages and lymphocytes, neoangiogenesis and fibrosis. The pattern of synovial reaction varies with disease duration and associated metabolic and structural changes in other joint tissues. Imaging modalities including Magnetic Resonance (MRI) and ultrasound (US) have proved useful in detecting and quantifying synovial abnormalities, but individual studies have varied in their methods of evaluation. Despite these differences, most studies have concluded that the presence of synovitis in OA is associated with more severe pain and joint dysfunction. In addition, synovitis may be predictive of faster rates of cartilage loss in certain patient populations. Recent studies have provided insights into the pathogenic mechanisms underlying the development of synovitis in OA. Available evidence suggests that the inflammatory process involves engagement of Toll-like receptors and activation of the complement cascade by degradation products of extracellular matrices of cartilage and other joint tissues. The ensuing synovial reaction can lead to synthesis and release of a wide variety of cytokines and chemokines. Some of these inflammatory mediators are detected in joint tissues and $\mathrm{SF}$ in OA and have catabolic effects on chondrocytes. These inflammatory mediators represent potential targets for therapeutic interventions designed to reduce both symptoms and structural joint damage in OA.

\section{Introduction}

Osteoarthritis (OA) is the most prevalent arthritic disease and a leading cause of disability. It affects approximately $34 \%$ of the United States population over age 65 (60). This common joint malady is characterized by marked alterations in the composition, structure and function of the articular cartilage. Research has focused on the impact of abnormal joint biomechanics on articular cartilage integrity and chondrocyte pathobiology, and this focus

C 2012 Elsevier Inc. All rights reserved

Corresponding Author: Carla R. Scanzello MD, PhD Rush University Medical Center 1611 W Harrison Street, Suite 510 Chicago, IL 60612 Office (312) 942-8268 Fax (312) 563-2267 Carla_Scanzello@ rush.edu.

Disclosures SRG has received research funding from Boehringer Ingelheim, and is a consultant for Bone Therapeutics and Fidia Pharmaceutical. CRS is a consultant for Cinkate, Corp. Rush University and Hospital for Special Surgery have filed a patent application for biomarkers in Osteoarthritis on behalf of CRS and SRG. 
has led to important insights into complex biochemical and biomechanical influences on chondrocyte behavior. However, recent evidence supports a newer perspective - that the clinical syndrome of "OA" affects not only articular cartilage, but also the integrity of multiple joint tissues. Pathologic cellular and structural changes in synovium, bone, ligaments, supporting musculature and fibrocartilagenous structures such as the meniscus are observed in OA, and what has emerged is an appreciation that OA is a "whole joint" disease. As adult articular cartilage is avascular and aneural, pathologic changes to noncartilagenous joint tissues are of particular interest in understanding the source of pain generation in OA. This review will focus on the impact of synovial inflammation (synovitis) in OA. We will discuss recent developments in our understanding of (I) the role of the SM in health and joint homeostasis, (II) the variability of synovitis in OA, (III) the clinical impact of synovitis on OA-related symptoms and disease progression, and (IV) pathways promoting synovitis relevant to OA.

\section{Functions of the Synovial Membrane}

The cellular elements of the SM are a major source of synovial fluid (SF) components; these components contribute to the unique functional properties of articular surfaces and modulate chondrocyte activity. Two important molecules produced by synovial lining cells, lubricin and hyaluronic acid (HA), help to protect and maintain the integrity of articular cartilage surfaces in diarthrodial joints (44). Together, these two molecules reduce friction by providing boundary lubrication at the articular surface. In addition, lubricin reduces pathologic deposition of proteins at the articular surface (82). In the setting of OA or after joint injury, the concentration and average molecular weight of HA, and the concentration of lubricin in SF are altered $(5,25,101)$, which adversely affects cartilage integrity. During OA progression, the synovial membrane is also a source of proinflammatory and catabolic products, including metalloproteinases and aggrecanases, which contribute to articular matrix degradation. Therefore, alterations in the SM can result in decreased concentrations of cartilage-protecting factors, and increased production of factors that contribute to the degradation of the articular matrix.

Articular cartilage has no intrinsic vasculature or lymphatic supply, and therefore it relies on adjacent tissues (subchondral bone and SM) to provide nutrients that are essential for maintaining the health of the chondrocyte and articular cartilage (13). It also relies on these adjacent tissues including the SM for removal of products of chondrocytic metabolism and articular matrix turnover. The SM acts as a semipermeable membrane controlling molecular traffic into and out of the joint space, maintaining the composition of SF, which is essential for preserving the normal physiologic state of articular cartilage. Under normal conditions, high molecular weight molecules like lubricin and HA are not readily permeable, while small molecules like growth factors and cytokines readily diffuse through the SM. This allows for the retention of high molecular weight (MW) lubricating molecules within the joint, while preventing high MW plasma proteins from entering and becoming deposited on the articular surface or altering the viscosity and composition of the SF. When synovial alterations such as inflammation and hyperplasia occur, the permeability of the membrane is altered. This change in permeability likely contributes to the decreased concentrations of HA and lubricin observed in SF in articular disease. Increases in HA are observed peripherally in the serum (35) in the setting of arthritis, and serum HA concentrations have been used as a marker of synovitis (70).

The clinical syndromes of synovial chondromatosis and osteochondromatosis suggest the existence of synovial resident cell populations that can differentiate along osteochondral cell lineages (22). Indeed, recent evidence points to a role for the SM as a "niche" that is a rich source of mesenchymal stem cells with multipotency, able to differentiate into multiple 
mature cell lineages including cartilage, bone, muscle and adipose tissue $(29,112)$. In this way the SM can participate in the regeneration and repair of injured or disrupted connective tissue components of the joint (32). The role of the SM in repairing defects in joint tissues suffered as the result of injury or disease warrants further investigation.

\section{Variability of Synovial Changes in OA}

Any discussion of the impact of synovitis on the natural history of OA must first begin with a description of the variability of SM changes and the numerous methods of detecting and quantifying synovitis. Synovitis can be defined histologically by the pattern of synovial changes (57); grossly by the visual appearance of the synovial lining in patients undergoing surgical procedures (3); or by the use of non-invasive imaging techniques including Magnetic Resonance Imaging (MRI) and Ultrasound (US). Although an argument can be made that the "gold standard" method of detection of OA is synovial histology (93), this requires an invasive biopsy that may not be applicable or acceptable to all patients. In fact, each of the approaches for characterizing SM changes, including histology and imaging, have provided important insights into the nature and variability of synovitis in the setting of OA.

\section{Synovial Histology}

Despite a long history of categorizing OA as a non-inflammatory form of arthritis, pathologic studies of SM specimens dating back to the 1980s described synovial inflammatory infiltrates of mononuclear cells, which in some cases were indistinguishable from infiltration observed in rheumatoid arthritis (RA) $(36,61,81)$. It was assumed that synovitis in OA occurred primarily in association with fragments of cartilage and bone (detritus), observed within the SM. The majority of these early studies utilized tissue specimens from patients undergoing total knee or hip arthroplasty, and so for many years it was unclear whether synovitis occurred at earlier stages of the disease. In 2002, Oehler and colleagues (73) performed a pathologic survey of synovial changes observed in OA including patients with earlier-stage disease undergoing arthroscopic procedures. These investigators identified four patterns of OA-associated "synoviopathy" including (i) hyperplastic, (ii) fibrotic, (iii) detritus-rich, and (vi) inflammatory. Capsular fibrosis characterized the fibrotic pattern, and macromolecular cartilage and bone debris defined the detritus-rich pattern. Both of these patterns were most often observed in patients with latestage disease. Synovial lining and villous hyperplasia were the most common findings, often seen in the context of the other patterns, but when observed in isolation constituted the hyperplastic pattern characteristic of early OA SM specimens. The inflammatory pattern was observed equally in both early and late OA, was not dependent on the presence of detritus, and was characterized by lymphocyte and plasma cell infiltration diffusely or in perivascular aggregates. Increased synovial vascularity described by others (109) was not specifically discussed, but the authors nicely illustrated that patterns of synovial change in $\mathrm{OA}$ are diverse, and may vary with the stage of disease. Figure 1 shows representative photomicrographs depicting synovial histopathologic changes observed in OA patients. Often, semi-quantitative synovial grading schemas combine common aspects of these patterns into a summed "synovitis" score. Using a three-component summed score, Krenn and colleagues determined that on average the synovitis of OA is low-grade in comparison to the high-grade synovitis of RA, but still distinguishable from normal SM $(56,77,97)$. These specific histopathologic patterns of synovitis have not yet provided strong links to clinical disease patterns or specific disease mechanisms. However, the presence of inflammatory synovial infiltrates has been associated with worse knee symptom scores measured by patient administered questionnaires (87), and the specific cellular nature of inflammatory infiltrates may differ between primary OA and OA secondary to conditions such as hemachromatosis (42). These studies point to the possibility that more in depth 
assessment of synovial histopathology may provide insights into disease variability or targetable mechanisms in the future.

\section{Synovial Imaging}

Although in some joints moderate to large synovial effusions can be identified with routine $\mathrm{x}$-ray techniques, in most cases, detection of the anatomically limited synovitis that is more characteristic of OA (than RA) requires advanced imaging techniques such as MRI and US. There are multiple MRI-based "whole-organ" grading systems that score specific anatomic features in the joint, including a semi-quantitative characterization of the magnitude of synovial change $(45,78)$. The most commonly used methods define synovitis according to the extent of synovial cavity distension or total synovial volume. These systems have been mostly applied to non-contrast imaging, but more recent studies have incorporated the use of contrast-enhanced MR imaging techniques to distinguish synovial thickening from effusion $(31,39)$. For example, in a recent study by Roemer et al. (85), the authors used both contrast-enhanced and non-enhanced images to examine a group of subjects with knee OA, and noted that synovitis was present in over $95 \%$ of the knee joints with an effusion, but also in $70 \%$ of knee joints in patients without an effusion. These findings suggest that in many cases synovial thickening may be independent of effusion, and may perhaps be a more reliable indicator of intra-articular pathology than the presence of joint effusion. Ultrasound has also been utilized to define the presence of synovitis in OA patients, and at least one report indicates that contrast-enhanced US may be as sensitive as contrast-enhanced MRI in detecting synovitis (99). Whether synovitis defined by imaging approaches corresponds to specific histologic features has been addressed by at least three groups. In 1995, FernandezMadrid et al. demonstrated that areas of synovitis observed on MR images in patients with knee OA corresponded to a low-grade chronic synovitis histologically (30). Loeuille and colleagues noted that areas of synovial thickening identified on MR images (65) correlated well with individual histologic changes, including inflammatory cell infiltration and lining hyperplasia. Most recently, Liu et al (64) showed a similar correlation between histologic features of inflammation and synovial thickening on MRI. These studies demonstrate the ability of current imaging techniques to non-invasively detect synovial inflammation, and provide further evidence that synovitis is an important contributor to OA pathobiology.

\section{Anatomic variation in synovitis}

The above sections describe two approaches, histology and imaging, utilized to identify synovitis in patients with OA. These approaches, as well as direct arthroscopic visualization, have documented anatomic variability in the location of the synovitis in the knee joint, which is most commonly studied. Early studies suggested that inflammation is more focal in OA than the widespread synovitis seen in RA, with synovium abutting cartilage lesions (36) or perimeniscal areas (3) preferentially involved. A relationship between symptoms and synovitis localized to the infrapatellar and suprapatellar areas has been demonstrated (43). In a recent study specifically addressing anatomic variation, synovitis detected by MRI was most commonly observed posterior to the posterior cruciate ligament (PCL) and in the suprapatellar region (85). Our own studies have focused on synovitis defined histologically in patients without radiographic evidence of OA undergoing surgery for meniscal tears (87). Although radiographically normal, the majority of these patients have cartilage abnormalities noted intraoperatively consistent with early stage OA. We examined the prevalence of synovial inflammation in these patients in three locations within the knee: suprapatellar pouch, medial gutter and lateral gutters. Of these locations, synovitis was most commonly detected in the suprapatellar pouch. There does not appear to be a single preferential location in which synovitis develops in the setting of all knee injuries and osteoarthritis, and the reasons for anatomic variation are unclear. Potential contributory factors include (i) biomechanical forces, (ii) local cartilage or other soft tissue injuries at 
specific locations, and (iii) differences in cellular or matrix composition at these anatomic sites that may be more conducive to the development of synovial inflammation.

\section{Clinical Impact of Synovial Inflammation (synovitis) in OA}

Many decades of research have demonstrated the clinical significance of synovitis in the setting of RA. These studies led to the development of therapies (i.e. the anti-TNF agents) that improved the clinical course and outcomes for patients with RA. It is only in the past decade, though, that research efforts have been directed at understanding how the low-grade synovitis of OA relates to disease manifestations. These efforts have provided substantial evidence that synovitis is associated with greater symptoms such as pain and degree of joint dysfunction, and may promote more rapid cartilage degeneration (Figure 2).

\section{Symptoms}

Despite different approaches employed for detection and characterization of synovitis (e.g. imaging or histologic assessment), published studies provide evidence of a correlation between synovial inflammation and symptoms such as pain, in patients with knee OA. Torres L, et al. (107) investigated the relationship between knee pain and specific joint pathology detected by MRI in patients with knee OA. They noted that synovitis or effusion, as well as meniscal tears and bone marrow lesions, were among findings that best correlated with knee pain measured on a visual analog scale (VAS). Others (43) specifically examined the relationship between pain and synovitis on MRI and noted that changes in pain scores over time varied with changes in synovitis, strengthening the notion of a causal relationship. A similar association between pain and synovitis was reported more recently (4) using contrast enhanced MRI. In that study, higher grades of synovitis conferred a 9-fold greater risk (95\% confidence interval 3.2-26.3) of having painful knee OA. Using serum HA as a marker of synovitis, Ishijima et al. (46) also demonstrated a relationship between synovitis and pain. We (87) contributed further evidence of an association between synovitis (defined histologically) and knee symptoms measured by the Lysholm score (which measures pain, swelling, limp, locking, instability, and functional disability on a single scale) in patients with early knee OA undergoing arthroscopic meniscectomy. Synovitis has not only been related to knee pain, but also to knee joint function using objective outcome measures of walking and stair-climbing times (100). One recent study of patients with end-stage knee OA undergoing joint replacement did not support a relationship between synovitis (64) and pain simply measured by a VAS. The reasons for this are unclear, but may be due to differences in patient populations studied, or differences in symptom assessments. We speculate that at advanced stages of knee OA where denuded bony surfaces are abutting each other, pain and symptoms may have multiple origins related to extensive structural alterations. Despite some disagreement in the literature, the majority of available studies provide compelling evidence that synovial inflammation is a rationale target for therapeutic intervention to control joint symptoms in OA. Future work should help define specific patient populations for whom targeting synovitis may have the greatest benefit.

\section{Disease Progression}

In 2005, Ayral and colleagues published a study demonstrating a relationship between synovitis and progression of cartilage erosion (3). This was a secondary analysis of 422 patients enrolled in a clinical trial with medial compartment knee OA who had been followed longitudinally for over one-year. Synovitis and cartilage integrity was documented by the visual appearance of the synovial membrane and cartilage surfaces during baseline arthroscopy. Progression of cartilage degeneration was determined by arthroscopic inspection one year after the original procedure. Approximately 50\% of the patients had synovial inflammation by their criteria, and this was associated with more severe baseline 
chondropathy. In addition, progression of cartilage pathology was statistically more advanced at one year in patients with synovial inflammation: $31.5 \%$ of patients with synovitis progressed compared to $12.9 \%$ of those without synovitis. Although an MRI based study in 2007 of patients with established OA (43) failed to corroborate these findings, a more recent study of 514 patients with knee pain but without radiographic knee OA demonstrated that effusion and synovitis were associated with subsequent development of cartilage loss at 30 months (adjusted $\mathrm{OR}=2.7,1.4-5.1, \mathrm{p}=0.002$ ) (84). Using US, Conaghan and colleagues also found evidence that synovial effusion was a predictor of progression to joint replacement in a 3 year prospective study (21). Although the majority of published studies support a relationship between synovitis and progression of joint damage, reasons for some disparate results are likely related to differences in patient populations, methods of defining synovitis, and anatomical areas assessed. In addition, molecular cross-talk between cartilage, synovium and other joint tissues could influence the impact of synovitis on structural joint changes, and this cross-talk very likely varies with the underlying cause of OA, stage of disease and extent of chondropathy.

\section{Disease Stage}

Despite differences in methods for detecting and defining synovitis, there is general agreement that the prevalence and severity of synovitis increases with advancing stage of OA defined by extent of cartilage lesions and radiographic changes. We showed that suprapatellar synovial inflammatory infiltrates were more prevalent (75\% vs. $43 \%$ ) and of higher histologic grade in patients with advanced knee OA than in a cohort of patients undergoing arthroscopic meniscectomy with no radiographic OA (87). Further support for a relationship between stage of knee OA and synovial changes is provided by the recent publication of Krasnokutsky, et al. (55). The authors assessed synovitis using 3T contrastenhanced MRI in a group of 58 patients with knee OA. Fixed-flexion radiographs were used to determine joint-space width, narrowing and disease stage by the Kellgren-Lawrence (KL) score. They showed that infrapatellar synovitis was present in $38 \%$ of patients with KL stage 2-3 disease, compared with $83 \%$ of patients with KL stage 4 disease. Measurements of joint space narrowing and width were consistent with their findings with KL score. Therefore, although synovitis is present early in disease and even at pre-radiographic stages, the proportion of patients with synovitis appears to increase with advancing structural deterioration. Whether any impact of synovitis on structural disease or symptoms will be the same at all stages remains to be determined.

\section{Pathways that may promote synovitis in OA}

There are multiple pathways and mediators that can directly influence the development and persistence of synovitis. Although historically this work has focused on RA, recent work suggests that some of these inflammatory pathways may be relevant to synovitis in both RA and OA. The available evidence has largely pointed to a role for innate immunity in OA (87). Innate immunity is the first level of immune system activation in response to inflammatory challenges. Recent data suggests that matrix fragments and products released during cellular stress can activate the innate immune response via pattern-recognition receptors known as Toll-like receptors (Figure 3 ). The ensuing cellular response culminates in activation of specific transcription factors, with nuclear-factor $\kappa \mathrm{B}(\mathrm{NF}-\mathrm{\kappa B})$ playing a prominent role. This transcription factor leads to production of multiple potent proinflammatory mediators including cytokines and chemokines that can cause local tissue damage. Many matrix metalloproteinases implicated in OA-related cartilage damage are dependent on the activity of NF- $\mathrm{\kappa B}$ as well $(68,38)$. Additional effector responses of innate immunity include activation of macrophages and the complement cascade. The role of activated synovial macrophages in promoting catabolic mediator production $(8,10)$ and 
osteophytosis (109) in OA animal models is well documented. Evidence for activation of the complement cascade has been provided more recently and will be reviewed (Figure 3).

\section{Toll-like receptors}

Activation of the innate response often begins with stimulation of pattern-recognition receptors, classically in the setting of infectious insult by microbial ligands (47). However, activation of the same pattern-recognition receptors involved in the response to pathogens occurs during cellular stress and extracellular matrix damage in the setting of sterile tissue injury (79). Under these circumstances, pattern-recognition receptors can be activated by endogenous damage-associated molecular patterns (DAMPS), rather than by microbial ligands. The disruption of matrix homeostasis that occurs in an osteoarthritic joint resembles a chronic injury (88).

There are ten TLRs (TLR-1 through 10) that are functional in humans. TLRs are constitutively expressed by a variety of cells including macrophages, but can be induced or up-regulated on other cells types, $(46,47)$. TLRs $1-7$ and 9 have been detected in SM in both OA and RA, and in vitro synovial fibroblasts respond to many microbial TLR agonists $(16,58,74,75,104)$. TLR activation in the SM is an important stimulus for NFrB activation and subsequent production of chemokines (e.g. IL-8 and CCL5) and cytokines (e.g. IL-1, IL-6 and TNF), which recruit and activate macrophages, granulocytes and lymphocytes (2), but chondrocytes also can serve as targets for TLR activation. Stimulating ligands have been identified for TLR1-9 (103), and include microbial and endogenous host products. Recent evidence has suggested that a number of endogenous products produced by matrix disruption or cellular stress can also bind and activate TLRs, even in the absence of obvious microbial infection. Many putative TLR ligands are modified in form or distribution, or increased in concentration in joint fluids or tissues in the setting of joint injury and OA. These include matrix components such as tenascin C $(72,19)$, fibronectin isoforms $(17,59)$, small molecular weight species of hyaluronic acid $(6,91,105,106)$ and biglycan $(9,23,80$, 90). Recently, certain plasma proteins increased in OA SF were demonstrated to activate macrophages in vitro via TLR-4 (98). In a murine model of autoimmune arthritis (1), TLR-4 deficiency resulted in reduced disease severity reflected by less synovial cellular influx, cartilage damage and bone erosion. On the other hand, TLR-2 knockout mice developed more severe disease, suggesting a protective role in this particular model. The regulatory processes involved in TLR activation are complex, and their role in promoting synovitis in OA is not fully established. However, targeting TLRs and the ligands and pathways that trigger their activation need to be explored as potential therapeutic approaches in OA.

In addition to the development of synovitis, TLR activation has implications for cartilage degeneration in OA. Enzymes involved in articular matrix turnover and degradation include matrix metalloproteinases (MMPs) and aggrecanases, which may be produced by both chondrocytes and synovial cell populations. In cartilage, TLR-2 and -4 are up-regulated specifically in lesional areas in patients with OA (52). A more recent study demonstrated that TLR2 and TLR4 signals are important in mediating catabolic responses and in increasing MMP-3 and MMP-13 production in murine cartilage explants (63). A recent genetic study in a Chinese population identified a TLR-9 polymorphism that is associated with the presence of radiographic knee OA (102). This report did not reveal an association with common TLR-2 or -4 polymorphisms, and how TLR-9 is linked to increased risk of $\mathrm{OA}$ is not yet clear. Taken together, though, these results implicate numerous members of the TLR family of pattern recognition receptors in inflammation, cartilage responses, and disease susceptibility in OA. A potential mechanism for activation of TLRs is depicted in Figure 3. 


\section{Complement activation}

The complement cascade is one of the major effector mechanisms of immune system activation. The three main pathways of complement activation (the classical, alternative and lectin pathways) are important in both innate (alternative and lectin pathways) as well as adaptive immune responses (the classical pathway, triggered by antibody/immune complexes), and have been extensively reviewed elsewhere (27). Soluble complement mediators such as $\mathrm{C} 3 \mathrm{a}, \mathrm{C} 3 \mathrm{~b}$ and $\mathrm{C} 5 \mathrm{a}$ are produced by serial proteolytic activation of this cascade, and these mediators promote inflammation and phagocytosis. The terminal complement protein complex, the membrane attack complex (MAC), can directly lyse target cells through pore formation when deposited on cellular membranes. Activation of the complement cascade is essential for effective clearance of many pathogens, but when complement activity is improperly regulated it can lead to extensive tissue damage. As early as 1988, complement deposition in synovial membranes of some patients with meniscal tears and cartilage degeneration was noted (15). Increased synovial complement component deposition in the setting of acute flare-ups of symptomatic OA has been demonstrated (54). Blood or serum leaking into the joint under circumstances of injury likely provides a source of complement proteins in many patients, but chondrocytes and synovial macrophages may also actively produce complement components and inhibitors (12). Using proteomic approaches, complement components and immunoglobulins have been identified in synovial fluids from OA patients (34) and in vesicles released from osteoarthritic cartilage in vitro (86). Several investigators have demonstrated that molecular components of the articular extracellular matrix may affect complement cascade activity. Fibromodulin (95), cartilage oligomeric matrix protein (COMP) (40), and osteoadherin (96) have been shown to activate the complement cascade, either the classical or alternative pathways. In contrast, other matrix components can act as complement inhibitors, such as the NC4 domain of Collagen IX (50). Exactly how complement deposition occurs in synovium and cartilage in the setting of OA, and the role of the complement cascade in OA pathogenesis remains to be determined. In recent collaborative studies (in press), mice with impaired ability to generate the MAC were partially protected from the development of OA, providing direct evidence for a role of the complement system in OA pathogenesis, at least in murine models (111). The potential pathway to complement activation in the OA joint is depicted in Figure 3.

\section{Soluble Inflammatory Mediators (Chemokines and Cytokines)}

Activation of pattern-recognition receptors and the complement cascade results in transcriptional activation of genes involved in the development of inflammation, most notably genes for soluble mediators such as cytokines and chemokines. These mediators may be produced by a variety of cell types, including macrophages, chondrocytes and synovial fibroblasts (51). A broad spectrum of cytokines and chemokines are detectable in joint tissues and fluids, and may prove useful as markers of the synovial inflammatory response. These same mediators may also play a role in development of joint inflammation and cartilage matrix destruction typical of OA. Some specific examples will be discussed below.

\section{IL-1}

Since the identification of IL-1 as a synovial factor that is able to induce cartilage destruction in vitro (26), much progress has been made regarding this cytokine's role in driving catabolic responses in chondrocytes. IL- $1 \beta$ signaling suppresses aggrecan (83) and collagen synthesis (37) in chondrocytes, and also can up-regulate the proteolytic enzymes ADAMTS-4 (108) and MMP-13 (71). However, IL-1 $\beta$ is not consistently elevated in the synovial fluid of OA patients $(53,92)$ and the endogenous IL-1 receptor antagonist, which blocks IL-1 activity, is produced by synoviocytes at higher levels in OA than in RA (33). 
Attempts to block IL-1 activity therapeutically in patients have been associated with only minimal symptom-reducing efficacy at best $(18,20)$. However, it is possible that IL-1 activity is important in specific clinical settings in OA. Production of active IL-1 requires activation of the NALP3 inflammasome; activation of the inflammasome by uric acid crystals has been implicated in flares of gouty arthritis (69). Other crystals, including basic calcium phosphate (76) and hydroxyapatite (48) have recently been shown to activate inflammasome-mediated IL-1 production. Both hydroxyapatite and basic calcium phosphate crystal deposition occurs in patients with OA. Therefore, it is possible that IL-1 is important in patients with OA and evidence of crystalline deposition.

\section{TNF- $\alpha$}

TNF- $a$ is readily detectable in SF in patients with OA (92). Like IL-1, TNF can activate chondrocyte-mediated catabolic protease production (51). The well-established clinical efficacy of TNF inhibition in the setting of RA, and the availability of blocking agents, led to trials of a TNF-inhibitor in an open-label pilot study to treat pain and inflammation in twelve patients with erosive hand OA (67). Like the IL-1 trials, this trial did not demonstrate significant efficacy, but improvement in pain and physical function scores was reported for some individuals. It remains to be seen whether different patient subsets will respond to targeted therapies blocking the actions of TNF.

\section{Common-gamma chain cytokines}

The perivascular inflammatory cell infiltrates observed in the OA synovium are largely composed of lymphocyte populations (7). Based on this observation, our group investigated the expression and activity of cytokines involved in lymphocyte biology in OA synovium. We focused our efforts on the common- $\gamma$ chain family of cytokines (including IL-2, IL-15, and IL-21) which are involved in recruitment, survival and activity of lymphocytes (89). IL-15 was consistently detectable and elevated in patients with early stage OA, compared with end-stage OA patients undergoing total knee arthroplasty. In rheumatoid synovial fibroblasts, TLR-2 and -4 stimulation were shown to induce IL-15 production in vitro (49). Both synoviocytes (89) and chondrocytes (Scanzello, unpublished results) from OA patients express the specific IL-15 receptor, suggesting there may be multiple cellular targets of IL-15. Serum IL-15 detected using a proteomic approach was associated with the presence and progression of radiographic OA (62). Studies by Long, et al, showed that IL-7, another common- $\gamma$ chain cytokine which activates lymphocytes, is produced by chondrocytes (66). This same study demonstrated that chondrocytes also express the IL-7 receptor and respond to IL-7 stimulation with increased production of matrix metalloproteinases and proteoglycan release. Further investigation into the importance of this cytokine family in disease models is necessary to determine whether they play a central role in progressive joint degeneration in $\mathrm{OA}$.

\section{Chemokines}

Chemokines are small molecules that play an important role in mediating recruitment and trafficking of inflammatory cells and mesenchymal progenitors. Many chemokines are produced in the joint tissues of patients with OA $(28,41)$. Thus, they represent potential therapeutic targets to either enhance repair mechanisms or decrease inflammation in patients with OA. We recently demonstrated that synovial inflammatory infiltrates were associated with expression of a distinct mRNA chemokine signature in patients with meniscal injury (87). The signature included IL-8, CCL5, CCL19 and its receptor CCR7. Expression of CCL19 and CCR7 was also associated with greater pre-operative symptoms, and based on these observations, their expression may have utility as biomarkers of early synovial inflammation. CCR7 is expressed by synovial fibroblasts, and mediates upregulation of VEGF in response to its ligand, CCL19 (14), suggesting a role in synovial angiogenesis. 
Other chemokines, specifically MCP-1 and MIP- $1 \beta$, have been associated with knee pain in patients undergoing arthroscopic procedures (24). An important role for MIP- $1 \gamma$ produced by $\mathrm{T}$ helper cells in the synovium was demonstrated in a murine model of OA induced by ligament transection (94). Similar to the cytokines discussed above, chemokines can induce matrix metalloproteinase (MMP)-3 and proteoglycan loss from articular cartilage (11). Furthermore, many chemokines may directly affect osteoclast-mediated remodeling of periarticular bone. In summary, chemokines represent a class of soluble inflammatory mediators that have pleiotropic effects on multiple joint tissues, and may contribute to inflammation and clinical symptoms in patients with OA. Further studies are needed to investigate the utility of targeting specific chemokines for symptom control or disease modification in OA.

\section{Conclusion}

There is increasing evidence that synovial inflammation plays a critical role in the symptoms and structural progression of OA. Importantly, synovitis has been shown to correlate with symptom severity, rate of cartilage degeneration and osteophytosis (Figure 2). The synovial response in OA is complex and variable with regards to histologic pattern (Figure 1), and in part this complexity can be attributed to changing patterns as disease evolves and progresses. Although structural joint damage in OA is a constant feature, the clinical syndrome of $\mathrm{OA}$ is quite variable, with differences in affected joint patterns, risk factors, rates of progression, and severity of symptoms. Further efforts to understand the cellular and molecular variability of OA-associated synovitis may provide insights into the clinical heterogeneity of the disease.

Pathways and soluble mediators that can promote or sustain synovitis also are quite diverse. In this review we highlighted two potential innate inflammatory mechanisms that may lead to development of synovitis in OA, the TLR pathway and the complement cascade (Figure 3). Furthermore, we highlighted the roles of cytokines and chemokines that play a role in the initiation and perpetuation of synovitis and OA symptoms. These pathways and mediators also may impact cartilage matrix homeostasis and peri-articular bone remodeling. In addition, the products associated with synovial inflammation may serve as surrogate markers of disease activity or responses to therapeutic interventions. Further understanding of mechanisms promoting synovial inflammation in OA may lead to identification of novel therapeutic targets for controlling symptoms and slowing structural progression in this disabling joint disease.

\section{Acknowledgments}

Supported by: Supported by 1K08 AR057859-02, Mentored Clinical Scientist Career Development Award, from the National Institute of Arthritis, Musculoskeletal and Skin Diseases (CRS).

\section{REFERENCES}

1. Abdollahi-Roodsaz S, Joosten LA, Koenders MI, Devesa I, Roelofs MF, Radstake TR, HeuvelmansJacobs M, Akira S, Nicklin MJ, Ribeiro-Dias F, van den Berg WB. Stimulation of TLR2 and TLR4 differentially skews the balance of T cells in a mouse model of arthritis. J Clin Invest. 2008; 118:205-16. [PubMed: 18060042]

2. Akira S, Takeda K. Toll-like receptor signalling. Nat Rev Immunol. 2004; 4:499-511. [PubMed: 15229469]

3. Ayral X, Pickering EH, Woodworth TG, Mackillop N, Dougados M. Synovitis: a potential predictive factor of structural progression of medial tibiofemoral knee osteoarthritis -- results of a 1 year longitudinal arthroscopic study in 422 patients. Osteoarthritis Cartilage. 2005; 13:361-7. [PubMed: 15882559] 
4. Baker K, Grainger A, Niu J, Clancy M, Guermazi A, Crema M, Hughes L, Buckwalter J, Wooley A, Nevitt M, Felson DT. Relation of synovitis to knee pain using contrast-enhanced MRIs. Ann Rheum Dis. 2010; 69:1779-83. [PubMed: 20472593]

5. Barker SA, Bayyuk SH, Brimacombe JS, Hawkins CF, Stacey M. Fingerprinting the Hyaluronic Acid Component of Normal and Pathological Synovial Fluids. Clin Chim Acta. 1963; 8:902-9. [PubMed: 14089562]

6. Belcher C, Yaqub R, Fawthrop F, Bayliss M, Doherty M. Synovial fluid chondroitin and keratan sulphate epitopes, glycosaminoglycans, and hyaluronan in arthritic and normal knees. Ann Rheum Dis. 1997; 56:299-307. [PubMed: 9175930]

7. Benito MJ, Veale DJ, FitzGerald O, van den Berg WB, Bresnihan B. Synovial tissue inflammation in early and late osteoarthritis. Ann Rheum Dis. 2005; 64:1263-7. [PubMed: 15731292]

8. Blom AB, van Lent PL, Libregts S, Holthuysen AE, van der Kraan PM, van Rooijen N, van den Berg WB. Crucial role of macrophages in matrix metalloproteinase-mediated cartilage destruction during experimental osteoarthritis: involvement of matrix metalloproteinase 3. Arthritis Rheum. 2007; 56:147-57. [PubMed: 17195217]

9. Bock HC, Michaeli P, Bode C, Schultz W, Kresse H, Herken R, Miosge N. The small proteoglycans decorin and biglycan in human articular cartilage of late-stage osteoarthritis. Osteoarthritis Cartilage. 2001; 9:654-63. [PubMed: 11597178]

10. Bondeson J, Blom AB, Wainwright S, Hughes C, Caterson B, van den Berg WB. The role of synovial macrophages and macrophage-produced mediators in driving inflammatory and destructive responses in osteoarthritis. Arthritis Rheum. 2010; 62:647-57. [PubMed: 20187160]

11. Borzi RM, Mazzetti I, Cattini L, Uguccioni M, Baggiolini M, Facchini A. Human chondrocytes express functional chemokine receptors and release matrix-degrading enzymes in response to $\mathrm{C}$-XC and C-C chemokines. Arthritis Rheum. 2000; 43:1734-41. [PubMed: 10943863]

12. Bradley K, North J, Saunders D, Schwaeble W, Jeziorska M, Woolley DE, Whaley K. Synthesis of classical pathway complement components by chondrocytes. Immunology. 1996; 88:648-56. [PubMed: 8881771]

13. Bresnihan, B.; Flanagan, AM. Synovium. In: Firestein, GS.; Budd, RC.; Harris, EDJ.; McInnes, IB.; Ruddy, S.; Sergent, JS., editors. Kelley's Textbook of Rheumatology I. Saunders Elsevier; 2009. p. 23-36.

14. Bruhl H, Mack M, Niedermeier M, Lochbaum D, Scholmerich J, Straub RH. Functional expression of the chemokine receptor CCR7 on fibroblast-like synoviocytes. Rheumatology (Oxford). 2008; 47:1771-4. [PubMed: 18838387]

15. Cantatore FP, Benazzo F, Ribatti D, Lapadula G, D'Amico S, Tursi A, Pipitone V. Early alteration of synovial membrane in osteoarthrosis. Clin Rheumatol. 1988; 7:214-9. [PubMed: 3046827]

16. Carrion M, Juarranz Y, Perez-Garcia S, Jimeno R, Pablos JL, Gomariz RP, Gutierrez-Canas I. RNA sensors in human osteoarthritis and rheumatoid arthritis synovial fibroblasts: immune regulation by vasoactive intestinal peptide. Arthritis Rheum. 2011; 63:1626-36. [PubMed: 21337319]

17. Chevalier X, Claudepierre P, Groult N, Zardi L, Hornebeck W. Presence of ED-A containing fibronectin in human articular cartilage from patients with osteoarthritis and rheumatoid arthritis. J Rheumatol. 1996; 23:1022-30. [PubMed: 8782135]

18. Chevalier X, Giraudeau B, Conrozier T, Marliere J, Kiefer P, Goupille P. Safety study of intraarticular injection of interleukin 1 receptor antagonist in patients with painful knee osteoarthritis: a multicenter study. J Rheumatol. 2005; 32:1317-23. [PubMed: 15996071]

19. Chevalier X, Groult N, Larget-Piet B, Zardi L, Hornebeck W. Tenascin distribution in articular cartilage from normal subjects and from patients with osteoarthritis and rheumatoid arthritis. Arthritis Rheum. 1994; 37:1013-22. [PubMed: 7517675]

20. Cohen SB, Proudman S, Kivitz AJ, Burch FX, Donohue JP, Burstein D, Sun YN, Banfield C, Vincent MS, Ni L, Zack DJ. A randomized, double-blind study of AMG 108 (a fully human monoclonal antibody to IL 1R1) in patients with osteoarthritis of the knee. Arthritis Res Ther. 2011; 13:R125. [PubMed: 21801403]

21. Conaghan PG, D'Agostino MA, Le Bars M, Baron G, Schmidely N, Wakefield R, Ravaud P, Grassi W, Martin-Mola E, So A, Backhaus M, Malaise M, Emery P, Dougados M. Clinical and 
ultrasonographic predictors of joint replacement for knee osteoarthritis: results from a large, 3year, prospective EULAR study. Ann Rheum Dis. 2010; 69:644-7. [PubMed: 19433410]

22. Crawford A, Frazer A, Lippitt JM, Buttle DJ, Smith T. A case of chondromatosis indicates a synovial stem. cell aetiology. Rheumatology (Oxford). 2006; 45:1529-33.

23. Cs-Szabo G, Roughley PJ, Plaas AH, Glant TT. Large and small proteoglycans of osteoarthritic and rheumatoid articular cartilage. Arthritis Rheum. 1995; 38:660-8. [PubMed: 7538297]

24. Cuellar JM, Scuderi GJ, Cuellar VG, Golish SR, Yeomans DC. Diagnostic utility of cytokine biomarkers in the evaluation of acute knee pain. J Bone Joint Surg Am. 2009; 91:2313-20. [PubMed: 19797564]

25. Dahl LB, Dahl IM, Engstrom-Laurent A, Granath K. Concentration and molecular weight of sodium hyaluronate in synovial fluid from patients with rheumatoid arthritis and other arthropathies. Ann Rheum Dis. 1985; 44:817-22. [PubMed: 4083937]

26. Dingle JT, Saklatvala J, Hembry R, Tyler J, Fell HB, Jubb R. A cartilage catabolic factor from synovium. Biochem J. 1979; 184:177-80. [PubMed: 534517]

27. Ehrnthaller C, Ignatius A, Gebhard F, Huber-Lang M. New insights of an old defense system: structure, function, and clinical relevance of the complement system. Mol Med. 2011; 17:317-29. [PubMed: 21046060]

28. Endres M, Andreas K, Kalwitz G, Freymann U, Neumann K, Ringe J, Sittinger M, Haupl T, Kaps C. Chemokine profile of synovial fluid from normal, osteoarthritis and rheumatoid arthritis patients: CCL25, CXCL10 and XCL1 recruit human subchondral mesenchymal progenitor cells. Osteoarthritis Cartilage. 2010; 18:1458-66. [PubMed: 20709179]

29. Fan J, Varshney RR, Ren L, Cai D, Wang DA. Synovium-derived mesenchymal stem cells: a new cell source for musculoskeletal regeneration. Tissue Eng Part B Rev. 2009; 15:75-86. [PubMed: 19196118]

30. Fernandez-Madrid F, Karvonen RL, Teitge RA, Miller PR, An T, Negendank WG. Synovial thickening detected by MR imaging in osteoarthritis of the knee confirmed by biopsy as synovitis. Magn Reson Imaging. 1995; 13:177-83. [PubMed: 7739358]

31. Fotinos-Hoyer AK, Guermazi A, Jara H, Eckstein F, Ozonoff A, Khard H, Norbash A, Bohndorf $\mathrm{K}$, Roemer FW. Assessment of synovitis in the osteoarthritic knee: Comparison between manual segmentation, semiautomated segmentation, and semiquantitative assessment using contrastenhanced fat-suppressed T1-weighted MRI. Magn Reson Med. 2010; 64:604-9. [PubMed: 20665803]

32. Fox DB, Warnock JJ. Cell-based Meniscal Tissue Engineering: A Case for Synoviocytes. Clin Orthop Relat Res. 2011

33. Fujikawa Y, Shingu M, Torisu T, Masumi S. Interleukin-1 receptor antagonist production in cultured synovial cells from patients with rheumatoid arthritis and osteoarthritis. Ann Rheum Dis. 1995; 54:318-20. [PubMed: 7763113]

34. Gobezie R, Kho A, Krastins B, Sarracino DA, Thornhill TS, Chase M, Millett PJ, Lee DM. High abundance synovial fluid proteome: distinct profiles in health and osteoarthritis. Arthritis Res Ther. 2007; 9:R36. [PubMed: 17407561]

35. Goldberg RL, Huff JP, Lenz ME, Glickman P, Katz R, Thonar EJ. Elevated plasma levels of hyaluronate in patients with osteoarthritis and rheumatoid arthritis. Arthritis Rheum. 1991; 34:799-807. [PubMed: 2059228]

36. Goldenberg DL, Egan MS, Cohen AS. Inflammatory synovitis in degenerative joint disease. J Rheumatol. 1982; 9:204-9. [PubMed: 7097678]

37. Goldring MB, Birkhead J, Sandell LJ, Kimura T, Krane SM. Interleukin 1 suppresses expression of cartilage-specific types II and IX collagens and increases types I and III collagens in human chondrocytes. J Clin Invest. 1988; 82:2026-37. [PubMed: 3264290]

38. Goldring MB, Otero M, Plumb DA, Dragomir C, Favero M, El Hachem K, Hashimoto K, Roach HI, Olivotto E, Borzi RM, Marcu KB. Roles of inflammatory and anabolic cytokines in cartilage metabolism: signals and multiple effectors converge upon MMP-13 regulation in osteoarthritis. Eur Cell Mater. 2011; 21:202-20. [PubMed: 21351054]

39. Guermazi A, Roemer FW, Hayashi D, Crema MD, Niu J, Zhang Y, Marra MD, Katur A, Lynch JA, El-Khoury GY, Baker K, Hughes LB, Nevitt MC, Felson DT. Assessment of synovitis with 
contrast-enhanced MRI using a whole-joint semiquantitative scoring system in people with, or at high risk of, knee osteoarthritis: the MOST study. Ann Rheum Dis. 2011; 70:805-11. [PubMed: 21187293]

40. Happonen KE, Saxne T, Aspberg A, Morgelin M, Heinegard D, Blom AM. Regulation of complement by cartilage oligomeric matrix protein allows for a novel molecular diagnostic principle in rheumatoid arthritis. Arthritis Rheum. 2010; 62:3574-83. [PubMed: 20737467]

41. Haringman JJ, Smeets TJ, Reinders-Blankert P, Tak PP. Chemokine and chemokine receptor expression in paired peripheral blood mononuclear cells and synovial tissue of patients with rheumatoid arthritis, osteoarthritis, and reactive arthritis. Ann Rheum Dis. 2006; 65:294-300. [PubMed: 16107514]

42. Heiland GR, Aigner E, Dallos T, Sahinbegovic E, Krenn V, Thaler C, Weiss G, Distler JH, Datz C, Schett G, Zwerina J. Synovial immunopathology in haemochromatosis arthropathy. Ann Rheum Dis. 2010; 69:1214-1219. [PubMed: 19933745]

43. Hill CL, Hunter DJ, Niu J, Clancy M, Guermazi A, Genant H, Gale D, Grainger A, Conaghan P, Felson DT. Synovitis detected on magnetic resonance imaging and its relation to pain and cartilage loss in knee osteoarthritis. Ann Rheum Dis. 2007; 66:1599-603. [PubMed: 17491096]

44. Hui AY, McCarty WJ, Masuda K, Firestein GS, Sah RL. A systems biology approach to synovial joint lubrication in health, injury, and disease. Wiley Interdiscip Rev Syst Biol Med. 2011

45. Hunter DJ, Lo GH, Gale D, Grainger AJ, Guermazi A, Conaghan PG. The reliability of a new scoring system for knee osteoarthritis MRI and the validity of bone marrow lesion assessment: BLOKS (Boston Leeds Osteoarthritis Knee Score). Ann Rheum Dis. 2008; 67:206-11. [PubMed: 17472995]

46. Ishijima M, Watari T, Naito K, Kaneko H, Futami I, Yoshimura-Ishida K, Tomonaga A, Yamaguchi H, Yamamoto T, Nagaoka I, Kurosawa H, Poole RA, Kaneko K. Relationships between biomarkers of cartilage, bone, synovial metabolism and knee pain provide insights into the origins of pain in early knee osteoarthritis. Arthritis Res Ther. 2011; 13:R22. [PubMed: 21320321]

47. Janeway CA Jr. Medzhitov R. Innate immune recognition. Annu Rev Immunol. 2002; 20:197-216. [PubMed: 11861602]

48. Jin C, Frayssinet P, Pelker R, Cwirka D, Hu B, Vignery A, Eisenbarth SC, Flavell RA. NLRP3 inflammasome plays a critical role in the pathogenesis of hydroxyapatite-associated arthropathy. Proc Natl Acad Sci U S A. 2011

49. Jung YO, Cho ML, Kang CM, Jhun JY, Park JS, Oh HJ, Min JK, Park SH, Kim HY. Toll-like receptor 2 and 4 combination engagement upregulate IL-15 synergistically in human rheumatoid synovial fibroblasts. Immunol Lett. 2007; 109:21-7. [PubMed: 17289161]

50. Kalchishkova N, Furst CM, Heinegard D, Blom AM. NC4 Domain of Cartilage-specific Collagen IX Inhibits Complement Directly Due to Attenuation of Membrane Attack Formation and Indirectly through Binding and Enhancing Activity of Complement Inhibitors C4B-binding Protein and Factor H. J Biol Chem. 2011; 286:27915-26. [PubMed: 21659506]

51. Kapoor M, Martel-Pelletier J, Lajeunesse D, Pelletier JP, Fahmi H. Role of proinflammatory cytokines in the pathophysiology of osteoarthritis. Nat Rev Rheumatol. 2011; 7:33-42. [PubMed: 21119608]

52. Kim HA, Cho ML, Choi HY, Yoon CS, Jhun JY, Oh HJ, Kim HY. The catabolic pathway mediated by Toll-like receptors in human osteoarthritic chondrocytes. Arthritis Rheum. 2006; 54:2152-63. [PubMed: 16802353]

53. Kokebie R, Aggarwal R, Lidder S, Hakimiyan AA, Rueger DC, Block JA, Chubinskaya S. The role of synovial fluid markers of catabolism and anabolism in osteoarthritis, rheumatoid arthritis and asymptomatic organ donors. Arthritis Res Ther. 2011; 13:R50. [PubMed: 21435227]

54. Konttinen YT, Ceponis A, Meri S, Vuorikoski A, Kortekangas P, Sorsa T, Sukura A, Santavirta S. Complement in acute and chronic arthritides: assessment of C3c, C9, and protectin (CD59) in synovial membrane. Ann Rheum Dis. 1996; 55:888-94. [PubMed: 9014582]

55. Krasnokutsky S, Belitskaya-Levy I, Bencardino J, Samuels J, Attur M, Regatte R, Rosenthal P, Greenberg J, Schweitzer M, Abramson SB, Rybak L. Quantitative magnetic resonance imaging 
evidence of synovial proliferation is associated with radiographic severity of knee osteoarthritis. Arthritis Rheum. 2011; 63:2983-91. [PubMed: 21647860]

56. Krenn V, Morawietz L, Burmester GR, Kinne RW, Mueller-Ladner U, Muller B, Haupl T. Synovitis score: discrimination between chronic low-grade and high-grade synovitis. Histopathology. 2006; 49:358-64. [PubMed: 16978198]

57. Krenn V, Morawietz L, Haupl T, Neidel J, Petersen I, Konig A. Grading of chronic synovitis--a histopathological grading system for molecular and diagnostic pathology. Pathol Res Pract. 2002; 198:317-25. [PubMed: 12092767]

58. Kyburz D, Rethage J, Seibl R, Lauener R, Gay RE, Carson DA, Gay S. Bacterial peptidoglycans but not $\mathrm{CpG}$ oligodeoxynucleotides activate synovial fibroblasts by toll-like receptor signaling. Arthritis Rheum. 2003; 48:642-50. [PubMed: 12632416]

59. Lasarte JJ, Casares N, Gorraiz M, Hervas-Stubbs S, Arribillaga L, Mansilla C, Durantez M, Llopiz D, Sarobe P, Borras-Cuesta F, Prieto J, Leclerc C. The extra domain A from fibronectin targets antigens to TLR4-expressing cells and induces cytotoxic T cell responses in vivo. J Immunol. 2007; 178:748-56. [PubMed: 17202335]

60. Lawrence RC, Felson DT, Helmick CG, Arnold LM, Choi H, Deyo RA, Gabriel S, Hirsch R, Hochberg MC, Hunder GG, Jordan JM, Katz JN, Kremers HM, Wolfe F. Estimates of the prevalence of arthritis and other rheumatic conditions in the United States. Part II. Arthritis Rheum. 2008; 58:26-35. [PubMed: 18163497]

61. Lindblad S, Hedfors E. Arthroscopic and immunohistologic characterization of knee joint synovitis in osteoarthritis. Arthritis Rheum. 1987; 30:1081-8. [PubMed: 3314876]

62. Ling SM, Patel DD, Garnero P, Zhan M, Vaduganathan M, Muller D, Taub D, Bathon JM, Hochberg M, Abernethy DR, Metter EJ, Ferrucci L. Serum protein signatures detect early radiographic osteoarthritis. Osteoarthritis Cartilage. 2009; 17:43-8. [PubMed: 18571442]

63. Liu-Bryan R, Terkeltaub R. Chondrocyte innate immune myeloid differentiation factor 88 dependent signaling drives procatabolic effects of the endogenous Toll-like receptor 2/Toll-like receptor 4 ligands low molecular weight hyaluronan and high mobility group box chromosomal protein 1 in mice. Arthritis Rheum. 2010; 62:2004-12. [PubMed: 20506365]

64. Liu L, Ishijima M, Futami I, Kaneko H, Kubota M, Kawasaki T, Matsumoto T, Kurihara H, Ning L, Xu Z, Ikeda H, Takazawa Y, Saita Y, Kimura Y, Xu S, Kaneko K, Kurosawa H. Correlation between synovitis detected on enhanced-magnetic resonance imaging and a histological analysis with a patient-oriented outcome measure for Japanese patients with end-stage knee osteoarthritis receiving joint replacement surgery. Clin Rheumatol. 2010; 29:1185-90. [PubMed: 20567866]

65. Loeuille D, Chary-Valckenaere I, Champigneulle J, Rat AC, Toussaint F, Pinzano-Watrin A, Goebel JC, Mainard D, Blum A, Pourel J, Netter P, Gillet P. Macroscopic and microscopic features of synovial membrane inflammation in the osteoarthritic knee: correlating magnetic resonance imaging findings with disease severity. Arthritis Rheum. 2005; 52:3492-501. [PubMed: 16255041]

66. Long D, Blake S, Song XY, Lark M, Loeser RF. Human articular chondrocytes produce IL-7 and respond to IL-7 with increased production of matrix metalloproteinase-13. Arthritis Res Ther. 2008; 10:R23. [PubMed: 18289383]

67. Magnano MD, Chakravarty EF, Broudy C, Chung L, Kelman A, Hillygus J, Genovese M. C. A pilot study of tumor necrosis factor inhibition in erosive/inflammatory osteoarthritis of the hands. $\mathrm{J}$ Rheumatol. 2007; 34:1323-7. [PubMed: 17516620]

68. Marcu KB, Otero M, Olivotto E, Borzi RM, Goldring MB. NF-kappaB signaling: multiple angles to target OA. Curr Drug Targets. 2010; 11:599-613. [PubMed: 20199390]

69. Martinon F, Petrilli V, Mayor A, Tardivel A, Tschopp J. Gout-associated uric acid crystals activate the NALP3 inflammasome. Nature. 2006; 440:237-41. [PubMed: 16407889]

70. Mazieres B, Garnero P, Gueguen A, Abbal M, Berdah L, Lequesne M, Nguyen M, Salles JP, Vignon E, Dougados M. Molecular markers of cartilage breakdown and synovitis at baseline as predictors of structural progression of hip osteoarthritis. The ECHODIAH Cohort. Ann Rheum Dis. 2006; 65:354-9. [PubMed: 16322084]

71. Mengshol JA, Vincenti MP, Coon CI, Barchowsky A, Brinckerhoff CE. Interleukin-1 induction of collagenase 3 (matrix metalloproteinase 13) gene expression in chondrocytes requires p38, c-Jun 
$\mathrm{N}$-terminal kinase, and nuclear factor kappaB: differential regulation of collagenase 1 and collagenase 3. Arthritis Rheum. 2000; 43:801-11. [PubMed: 10765924]

72. Midwood K, Sacre S, Piccinini AM, Inglis J, Trebaul A, Chan E, Drexler S, Sofat N, Kashiwagi M, Orend G, Brennan F, Foxwell B. Tenascin-C is an endogenous activator of Toll-like receptor 4 that is essential for maintaining inflammation in arthritic joint disease. Nat Med. 2009; 15:774-80. [PubMed: 19561617]

73. Oehler S, Neureiter D, Meyer-Scholten C, Aigner T. Subtyping of osteoarthritic synoviopathy. Clin Exp Rheumatol. 2002; 20:633-40. [PubMed: 12412193]

74. Ospelt C, Brentano F, Rengel Y, Stanczyk J, Kolling C, Tak PP, Gay RE, Gay S, Kyburz D. Overexpression of toll-like receptors 3 and 4 in synovial tissue from patients with early rheumatoid arthritis: toll-like receptor expression in early and longstanding arthritis. Arthritis Rheum. 2008; 58:3684-92. [PubMed: 19035519]

75. Ozawa T, Koyama K, Ando T, Ohnuma Y, Hatsushika K, Ohba T, Sugiyama H, Hamada Y, Ogawa H, Okumura K, Nakao A. Thymic stromal lymphopoietin secretion of synovial fibroblasts is positively and negatively regulated by Toll-like receptors/nuclear factor-kappaB pathway and interferon-gamma/dexamethasone. Mod Rheumatol. 2007; 17:459-63. [PubMed: 18084696]

76. Pazar B, Ea HK, Narayan S, Kolly L, Bagnoud N, Chobaz V, Roger T, Liote F, So A, Busso N. Basic calcium phosphate crystals induce monocyte/macrophage IL-1beta secretion through the NLRP3 inflammasome in vitro. J Immunol. 2011; 186:2495-502. [PubMed: 21239716]

77. Pessler F, Dai L, Diaz-Torne D, Gomez-Vaquero C, Paessler ME, Zheng DH, Einhorn E, Range U, Schumacher HR. The synovitis of "non-inflammatory" orthopedic arthropathies: a quantitative histologic and immunohistochemical analysis. Ann Rheum Dis. 2008

78. Peterfy CG, Guermazi A, Zaim S, Tirman PF, Miaux Y, White D, Kothari M, Lu Y, Fye K, Zhao S, Genant HK. Whole-Organ Magnetic Resonance Imaging Score (WORMS) of the knee in osteoarthritis. Osteoarthritis Cartilage. 2004; 12:177-90. [PubMed: 14972335]

79. Piccinini AM, Midwood KS. DAMPening inflammation by modulating TLR signalling. Mediators Inflamm. 20102010.

80. Poole AR, Rosenberg LC, Reiner A, Ionescu M, Bogoch E, Roughley PJ. Contents and distributions of the proteoglycans decorin and biglycan in normal and osteoarthritic human articular cartilage. J Orthop Res. 1996; 14:681-9. [PubMed: 8893759]

81. Revell PA, Mayston V, Lalor P, Mapp P. The synovial membrane in osteoarthritis: a histological study including the characterisation of the cellular infiltrate present in inflammatory osteoarthritis using monoclonal antibodies. Ann Rheum Dis. 1988; 47:300-7. [PubMed: 3259125]

82. Rhee DK, Marcelino J, Baker M, Gong Y, Smits P, Lefebvre V, Jay GD, Stewart M, Wang H, Warman ML, Carpten JD. The secreted glycoprotein lubricin protects cartilage surfaces and inhibits synovial cell overgrowth. J Clin Invest. 2005; 115:622-31. [PubMed: 15719068]

83. Richardson DW, Dodge GR. Effects of interleukin-1beta and tumor necrosis factor-alpha on expression of matrix-related genes by cultured equine articular chondrocytes. Am J Vet Res. 2000; 61:624-30. [PubMed: 10850836]

84. Roemer FW, Guermazi A, Felson DT, Niu J, Nevitt MC, Crema MD, Lynch JA, Lewis CE, Torner J, Zhang Y. Presence of MRI-detected joint effusion and synovitis increases the risk of cartilage loss in knees without osteoarthritis at 30-month follow-up: the MOST study. Ann Rheum Dis. 2011

85. Roemer FW, Kassim Javaid M, Guermazi A, Thomas M, Kiran A, Keen R, King L, Arden NK. Anatomical distribution of synovitis in knee osteoarthritis and its association with joint effusion assessed on non-enhanced and contrast-enhanced MRI. Osteoarthritis Cartilage. 2010; 18:126974. [PubMed: 20691796]

86. Rosenthal AK, Gohr CM, Ninomiya J, Wakim BT. Proteomic analysis of articular cartilage vesicles from normal and osteoarthritic cartilage. Arthritis Rheum. 2011; 63:401-11. [PubMed: 21279997]

87. Scanzello CR, McKeon B, Swaim BH, DiCarlo E, Asomugha EU, Kanda V, Nair A, Lee DM, Richmond JC, Katz JN, Crow MK, Goldring SR. Synovial inflammation in patients undergoing arthroscopic meniscectomy: molecular characterization and relationship to symptoms. Arthritis Rheum. 2011; 63:391-400. [PubMed: 21279996] 
88. Scanzello CR, Plaas A, Crow MK. Innate immune system activation in osteoarthritis: is osteoarthritis a chronic wound? Curr Opin Rheumatol. 2008; 20:565-72. [PubMed: 18698179]

89. Scanzello CR, Umoh E, Pessler F, Diaz-Torne C, Miles T, Dicarlo E, Potter HG, Mandl L, Marx R, Rodeo S, Goldring SR, Crow MK. Local cytokine profiles in knee osteoarthritis: elevated synovial fluid interleukin-15 differentiates early from end-stage disease. Osteoarthritis Cartilage. 2009; 17:1040-8. [PubMed: 19289234]

90. Schaefer L, Babelova A, Kiss E, Hausser HJ, Baliova M, Krzyzankova M, Marsche G, Young MF, Mihalik D, Gotte M, Malle E, Schaefer RM, Grone HJ. The matrix component biglycan is proinflammatory and signals through Toll-like receptors 4 and 2 in macrophages. J Clin Invest. 2005; 115:2223-33. [PubMed: 16025156]

91. Scheibner KA, Lutz MA, Boodoo S, Fenton MJ, Powell JD, Horton MR. Hyaluronan fragments act as an endogenous danger signal by engaging TLR2. J Immunol. 2006; 177:1272-81. [PubMed: 16818787]

92. Schlaak JF, Pfers I, Meyer Zum Buschenfelde KH, Marker-Hermann E. Different cytokine profiles in the synovial fluid of patients with osteoarthritis, rheumatoid arthritis and seronegative spondylarthropathies. Clin Exp Rheumatol. 1996; 14:155-62. [PubMed: 8737721]

93. Sellam J, Berenbaum F. The role of synovitis in pathophysiology and clinical symptoms of osteoarthritis. Nat Rev Rheumatol. 2010; 6:625-35. [PubMed: 20924410]

94. Shen PC, Wu CL, Jou IM, Lee CH, Juan HY, Lee PJ, Chen SH, Hsieh JL. T helper cells promote disease progression of osteoarthritis by inducing macrophage inflammatory protein-1gamma. Osteoarthritis Cartilage. 2011; 19:728-36. [PubMed: 21376128]

95. Sjoberg A, Onnerfjord P, Morgelin M, Heinegard D, Blom AM. The extracellular matrix and inflammation: fibromodulin activates the classical pathway of complement by directly binding C1q. J Biol Chem. 2005; 280:32301-8. [PubMed: 16046396]

96. Sjoberg AP, Manderson GA, Morgelin M, Day AJ, Heinegard D, Blom AM. Short leucine-rich glycoproteins of the extracellular matrix display diverse patterns of complement interaction and activation. Mol Immunol. 2009; 46:830-9. [PubMed: 18962898]

97. Slansky E, Li J, Haupl T, Morawietz L, Krenn V, Pessler F. Quantitative determination of the diagnostic accuracy of the synovitis score and its components. Histopathology. 2010; 57:436-43. [PubMed: 20840673]

98. Sohn DH, Sokolove J, Sharpe O, Erhart JC, Chandra PE, Lahey LJ, Lindstrom TM, Hwang I, Boyer KA, Andriacchi TP, Robinson WH. Arthritis Res Ther. 2012; 14(1):R7. 98. [PubMed: 22225630]

99. Song IH, Althoff CE, Hermann KG, Scheel AK, Knetsch T, Burmester GR, Backhaus M. Contrastenhanced ultrasound in monitoring the efficacy of a bradykinin receptor 2 antagonist in painful knee osteoarthritis compared with MRI. Ann Rheum Dis. 2009; 68:75-83. [PubMed: 18375537]

100. Sowers M, Karvonen-Gutierrez CA, Jacobson JA, Jiang Y, Yosef M. Associations of anatomical measures from MRI with radiographically defined knee osteoarthritis score, pain, and physical functioning. J Bone Joint Surg Am. 2011; 93:241-51. [PubMed: 21266638]

101. Stafford CT, Niedermeier W, Holley HL, Pigman W. Studies on the Concentration and Intrinsic Viscosity of Hyaluronic Acid in Synovial Fluids of Patients with Rheumatic Diseases. Ann Rheum Dis. 1964; 23:152-7. [PubMed: 14130036]

102. Su SL, Yang HY, Lee CH, Huang GS, Salter DM, Lee HS. The (-1486T/C) promoter polymorphism of the TLR-9 gene is associated with end-stage knee osteoarthritis in a Chinese population. J Orthop Res. 2011

103. Takeda K, Akira S. Toll-like receptors in innate immunity. Int Immunol. 2005; 17:1-14. [PubMed: 15585605]

104. Tamaki Y, Takakubo Y, Hirayama T, Konttinen YT, Goodman SB, Yamakawa M, Takagi M. Expression of Toll-like receptors and their signaling pathways in rheumatoid synovitis. J Rheumatol. 2011; 38:810-20. [PubMed: 21324962]

105. Taylor KR, Trowbridge JM, Rudisill JA, Termeer CC, Simon JC, Gallo RL. Hyaluronan fragments stimulate endothelial recognition of injury through TLR4. J Biol Chem. 2004; 279:17079-84. [PubMed: 14764599] 
106. Termeer C, Benedix F, Sleeman J, Fieber C, Voith U, Ahrens T, Miyake K, Freudenberg M, Galanos C, Simon JC. Oligosaccharides of Hyaluronan activate dendritic cells via toll-like receptor 4. J Exp Med. 2002; 195:99-111. [PubMed: 11781369]

107. Torres L, Dunlop DD, Peterfy C, Guermazi A, Prasad P, Hayes KW, Song J, Cahue S, Chang A, Marshall M, Sharma L. The relationship between specific tissue lesions and pain severity in persons with knee osteoarthritis. Osteoarthritis Cartilage. 2006; 14:1033-40. [PubMed: 16713310]

108. Tortorella MD, Burn TC, Pratta MA, Abbaszade I, Hollis JM, Liu R, Rosenfeld SA, Copeland RA, Decicco CP, Wynn R, Rockwell A, Yang F, Duke JL, Solomon K, George H, Bruckner R, Nagase H, Itoh Y, Ellis DM, Ross H, Wiswall BH, Murphy K, Hillman MC Jr. Hollis GF, Newton RC, Magolda RL, Trzaskos JM, Arner EC. Purification and cloning of aggrecanase-1: a member of the ADAMTS family of proteins. Science. 1999; 284:1664-6. [PubMed: 10356395]

109. van Lent PL, Blom AB, van der Kraan P, Holthuysen AE, Vitters E, van Rooijen N, Smeets RL, Nabbe KC, van den Berg WB. Crucial role of synovial lining macrophages in the promotion of transforming growth factor beta-mediated osteophyte formation. Arthritis Rheum. 2004; 50:10311. [PubMed: 14730606]

110. Walsh DA, Bonnet CS, Turner EL, Wilson D, Situ M, McWilliams DF. Angiogenesis in the synovium and at the osteochondral junction in osteoarthritis. Osteoarthritis Cartilage. 2007; 15:743-51. [PubMed: 17376709]

111. Wang Q, Rozelle A, Lepus C, Scanzello C, Song J, Larsen D, Crish J, Bebek G, Ritter S, Lindstrom T, Hwang I, Wong H, Punzi L, Encarnacion A, Shamloo M, Goodman S, Wyss-Coray T, Goldring S, Gobezie R, Crow M, Holers V, Lee D, Robinson W. Identification of a central role for complement in osteoarthritis. Nature Medicine. 2011; 17:1674-9.

112. Yang Z, Schmitt JF, Lee EH. Immunohistochemical analysis of human mesenchymal stem cells differentiating into chondrogenic, osteogenic, and adipogenic lineages. Methods Mol Biol. 2011; 698:353-66. [PubMed: 21431531] 


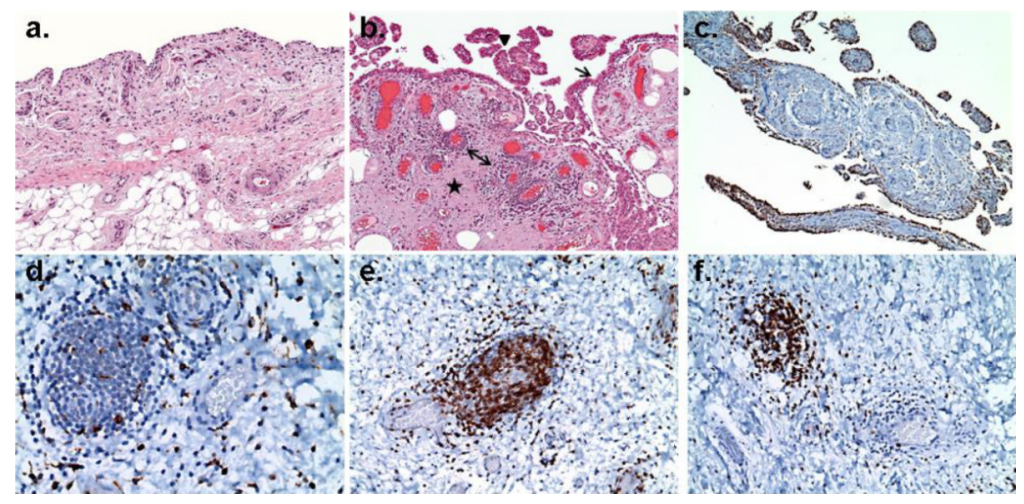

Figure 1. Representative synovial histopathology observed in osteoarthritis

Paraffin-embedded, formalin fixed thin sections of synovial membrane from patients with OA undergoing total joint arthroplasty. Hematoxylin and Eosin (panels a and b, 2x) or immunohistochemical stains with specific monoclonal antibodies against a macrophage

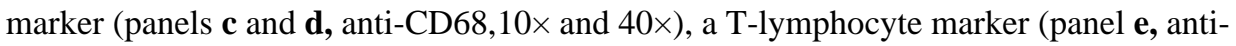
CD3, 40×), or a B-lymphocyte marker (panel f, anti-CD20, 40×). Panel a depicts normal appearing synovial membrane with a thin lining layer and loose connective tissue subintimal layer. The section in panel $\mathbf{b}$ demonstrates synovial lining hyperplasia (arrow), villous hyperplasia (arrowhead), fibrosis (star) and perivascular mononuclear cell infiltrates (double-headed arrow) which are histopathologic features often observed in OA. Panel c \& d depict the two typical distributions of CD68+ cells in OA SM: (c) concentrated in the synovial lining layer and (d) scattered throughout the subintimal layer and the perivascular infiltrates. Panel $\mathbf{e}$ and $\mathbf{f}$ demonstrate that the majority of cells within the perivascular infiltrates express markers of (e) T and (f) B lymphocytes. (Immunostaining courtesy of Frank Pessler, MD PhD, Section of Rheumatology/Immunology, Klinik und Poliklinik für Kinder- und Jugendmedizin, Dresden, Germany. Photomicrographs generously provided by Edward DiCarlo, MD, Department of Pathology and Laboratory Medicine, Hospital for Special Surgery, New York NY.) 


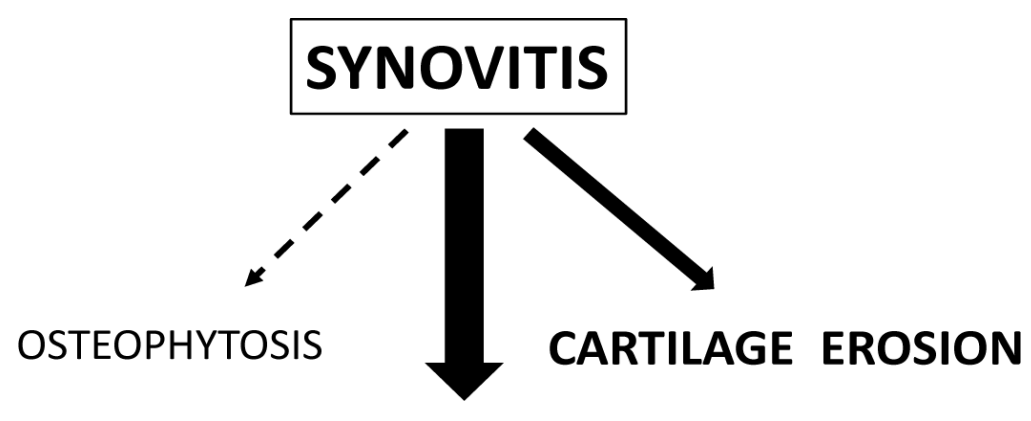

\section{SYMPTOMS}

Figure 2. The impact of synovitis on disease manifestations in OA

There is a substantial body of evidence from multiple sources demonstrating a relationship between the presence of synovitis and symptoms such as pain, swelling, and joint dysfunction in knee OA patients. Evidence from a smaller number of arthroscopic and imaging studies suggests that the presence of synovitis may be associated with faster rates of cartilage erosion in OA. Although not yet demonstrated in patients, additional studies of animal models suggest that synovial macrophages, increased in synovitis, may be involved in osteophyte formation in OA. 


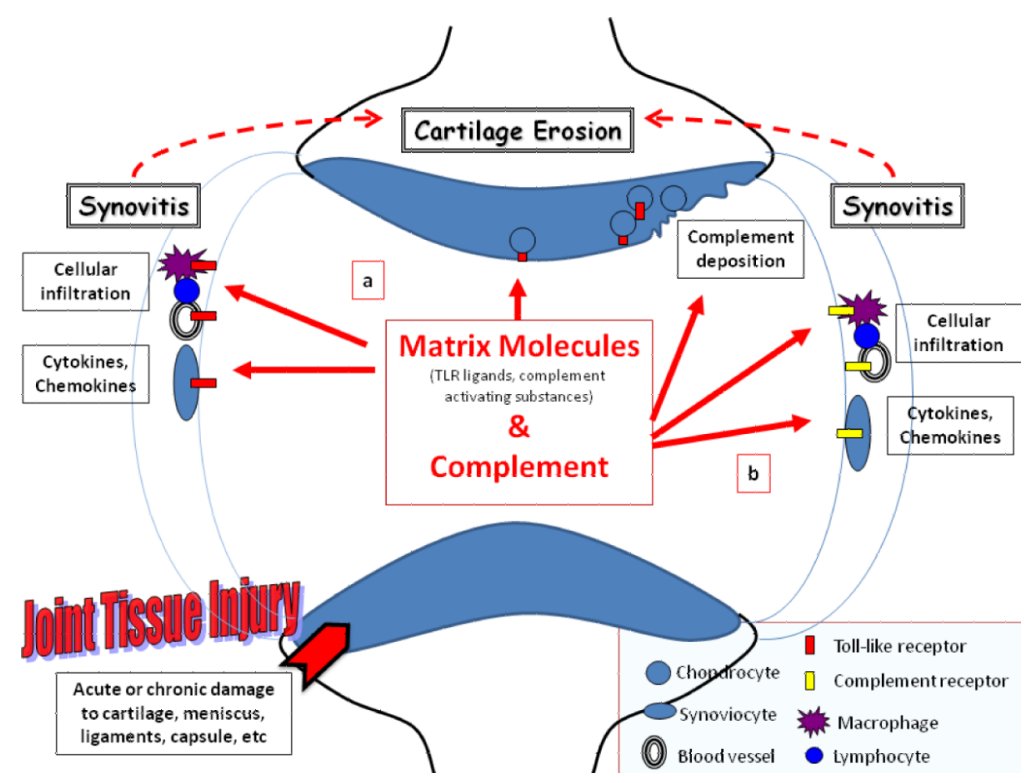

Figure 3. A model of Toll-like Receptor (a) and complement activation (b) in the joint leading to synovitis and potentiation of cartilage erosion in $\mathrm{OA}$

Joint tissue injury, either acute traumatic injury to joint tissues, or chronic cartilage damage occurring throughout the course of OA, can lead to the elaboration of both matrix molecules and complement components that are released into the synovial fluid. Some matrix molecules may act as TLR agonists while others can activate the complement cascade. TLR activation is depicted on the left (a). Certain matrix components increased in OA and injury can interact with TLRs on resident and infiltrating cells of the synovium. In addition, TLR expression on chondrocytes is increased in lesional areas of cartilage. Binding of these ligands to TLRs leads to the generation of inflammatory cytokines and chemokines, which can promote cellular infiltration, the hallmark of synovitis. This molecular and cellular inflammation can then potentiate cartilage erosion via production of enzymatic mediators of matrix degradation. Complement activation in the joint is depicted on the right (b). Synovial inflammation can lead to leakage of plasma complement proteins into the joint, but chondrocytes and the SM itself also may be a source of complement components. Articular matrix components distinct from those activating TLRs have been demonstrated to bind complement components, leading to activation of the complement cascade and generation of active complement proteins. These proteins also can bind to receptors or deposit on cells of the synovium leading to increased cytokine production, and increased synoviial inflammation. 